\title{
Increased risk of cognitive and functional decline in patients with atrial fibrillation: results of the ONTARGET and TRANSCEND studies
}

\author{
Irene Marzona MSc PharmD, Martin O'Donnell MB PhD, Koon Teo MB PhD, Peggy Gao MSc, \\ Craig Anderson MD PhD, Jackie Bosch BScOT MSc, Salim Yusuf MD DPhil
}

\begin{abstract}
Background: The role of atrial fibrillation in cognitive impairment and dementia, independent of stroke, is uncertain. We sought to determine the association of atrial fibrillation with cognitive and physical impairment in a large group of patients at high cardiovascular risk.
\end{abstract}

Methods: We conducted a post-hoc analysis of two randomized controlled trials involving 31546 patients, the aims of which were to evaluate the efficacy of treatment with ramipril plus telmisartan (ONTARGET) or telmisartan alone (TRANSCEND) in reducing cardiovascular disease. We evaluated the cognitive function of participants at baseline and after two and five years using the Mini-Mental State Examination (MMSE). In addition, we recorded incident dementia, loss of independence in activities of daily living and admission to long-term care facilities. We used a Cox regression model adjusting for main confounders to determine the association between atrial fibrillation and our primary outcomes: a decrease of three or more points in MMSE score, incident dementia, loss of independence in performing activities of daily living and admission to long-term care.

Results: We enrolled 31506 participants for whom complete information on atrial fibrillation was available, $70.4 \%$ of whom were men. The mean age of participants was 66.5 years, and the mean baseline MMSE score was 27.7 (standard deviation 2.9) points. At baseline, 1016 participants $(3.3 \%)$ had atrial fibrillation, with the condition developing in an additional 2052 participants $(6.5 \%)$ during a median follow-up of 56 months. Atrial fibrillation was associated with an increased risk of cognitive decline (hazard ratio [HR] 1.14, 95\% confidence interval [CI] 1.031.26), new dementia (HR 1.30,95\% Cl 1.14-1.49), loss of independence in performing activities of daily living ( $\mathrm{HR} 1.35,95 \% \mathrm{Cl} 1.19-1.54)$ and admission to long-term care facilities (HR 1.53, $95 \% \mathrm{Cl} 1.31-1.79)$. Results were consistent among participants with and without stroke or receiving antihypertensive drugs.

Interpretation: Cognitive and functional decline are important consequences of atrial fibrillation, even in the absence of overt stroke.

\section{$\mathrm{A}$} trial fibrillation is an important and modifiable cause of ischemic stroke, which may result in considerable physical and cognitive disability. ${ }^{1}$ In addition, atrial fibrillation is associated with an increased risk of covert cerebral infarction, which is reported in about one-quarter of patients with atrial fibrillation who undergo magnetic resonance imaging of the brain. ${ }^{2}$ Thus, atrial fibrillation may be an important determinant of cognitive and functional decline, even in the absence of clinical ischemic stroke. However, previous epidemiologic studies evaluating atrial fibrillation's association with cognitive function have been inconsistent, ${ }^{3-13}$ and very few have evaluated its association with functional outcomes. ${ }^{14}$
A recent systematic review showed convincing evidence of an association between atrial fibrillation and dementia in patients with a history of stroke, but it concluded that there was considerable uncertainty of a link between atrial fibrillation and dementia in patients with no history of stroke. ${ }^{15}$ Large prospective cohort studies are required to determine a true association between atrial fibrillation and cognitive outcomes.

In this study, we sought to determine the prospective association between atrial fibrillation and cognitive decline, loss of independence in activities of daily living and admission to longterm care facilities, using data from a large group of patients included in the ONTARGET and TRANSCEND trials. ${ }^{16,17}$
Competing interests: Martin O'Donnell has received grants, consulting fees and payment for lectures from BoehringerIngelheim. Koon Teo has received research grants from the Canadian Institutes of Health Research and the

Heart and Stroke Foundation of Ontario. Craig Anderson has received project and fellowship grants from the National Health and Medical Research Council of Australia. No other competing interests were declared.

This article has been peer reviewed.

Correspondence to: Dr. Irene Marzona, irene.marzona@phri.ca

CMAJ 2012. DOI:10.1503 /cmaj.111173 


\section{Methods}

\section{Study population}

All of the participants from the ONTARGET and TRANSCEND trials, recruited from 733 centres in 40 countries between November 2001 and May 2004 and for whom complete information on atrial fibrillation at baseline was available, were eligible for inclusion in our study. For participation in either trial, patients needed to be at high risk of cardiovascular disease, defined as 55 years of age or older with a history of either established cardiovascular disease or diabetes mellitus with evidence of end-organ damage. Patients with heart failure, substantial valvular disease or uncontrolled hypertension were excluded.

ONTARGET was a randomized, controlled, double-blind, double-dummy trial involving 25620 patients, which compared the combination of telmisartan $(80 \mathrm{mg} / \mathrm{d})$ plus ramipril $(10 \mathrm{mg} / \mathrm{d})$ with telmisartan alone. TRANSCEND was a randomized, controlled, double-blind trial involving 5926 patients with intolerance to angiotensin-converting enzyme inhibitors, which compared telmisartan $(80 \mathrm{mg} / \mathrm{d})$ to placebo. In each study, after randomization, patients were followed-up at six weeks, six months, and every six months thereafter for a median of 56 months. The primary outcome for both studies was the composite of cardiovascular death, myocardial infarction, stroke or admission to hospital for heart failure. At each of the follow-up visits, major vascular events and new atrial fibrillation were recorded for all participants. Approval was obtained from the institutional ethics committee of each centre and all participants provided written informed consent. The primary results of both trials have been published previously. ${ }^{16,17}$

\section{Outcome measures}

Our primary outcomes were decreased cognitive function, new dementia, inability to perform activities of daily living independently and admission to long-term care.

We assessed cognitive function at baseline, at two years' follow-up and during each patient's penultimate visit (i.e., the visit immediately before the final scheduled follow-up appointment) using the Mini-Mental State Examination (MMSE). Contextually appropriate translations of the MMSE were used in some countries (i.e., Austria, Belgium, Czech Republic, Germany, Greece, Netherlands, Finland, Norway, Sweden, South Africa and South Korea), but most investigators administered the standard English version in the local language. Investigators and coordinators underwent training before the study started, and monitoring visits by professionally trained personnel from a contract research organization during the course of the study ensured uniform adherence to procedures. A manual of operations provided a detailed outline of the protocol, and the case report forms included instructions for standardized completion.

The MMSE includes 10 domain items that measure orientation to time (5 points), orientation to place (5 points), registration ( 3 points), attention and calculation (5 points), recall (3 points), naming and repetition (3 points), comprehension (3 points), reading ability (1 point), writing ability (1 point) and design copy (a brief measure of visual construction; 1 point). One point is awarded for each successfully completed item on the MMSE, to a maximum of 30 points; the higher the score, the better the cognitive performance.

We defined cognitive decline as a decrease of three or more points in MMSE score between baseline and follow-up, as reported in previous studies. ${ }^{18,19}$ We defined new dementia as a new diagnosis of dementia, reported severe cognitive impairment or an MMSE score of 23 points or less ${ }^{20}$ during follow-up. New reports of dementia and severe cognitive impairment were recorded at two follow-up visits (at 2.5 years and at the penultimate visit). During these visits, investigators determined and documented whether participants had been admitted to long-term care and whether they required assistance to perform activities of daily living

\section{Confounding variables}

We collected data on all variables at the time of randomization. Education was categorized as none, 1-8 years, 9-12 years, trade school/ technical college and college/university. Participants were considered to be English-speaking if they were recruited from a site in an Englishspeaking country. We determined history of myocardial infarction, stroke, hypertension, diabetes mellitus and smoking using patient reports. We estimated creatinine clearance using the Cockcroft-Gault formula. ${ }^{21}$ We categorized smoking as never (the reference group), former or current. We categorized physical activity as mainly sedentary (reference), exercise two to four times per week, exercise five to six times per week and daily exercise. We categorized alcohol consumption as never/former, moderate and binge drinking (i.e., five or more drinks on a single occasion in the preceding month). We determined the presence of sleep apnea based on patient-reported previous diagnosis. We recorded the use of antithrombotic agents such as antiplatelet therapy or oral anticoagulants (i.e., vitamin $\mathrm{K}$ antagonists) at the initial visit. Participants self-reported ethnicity. 
Table 1: Characteristics of 31506 participants from the ONTARGET and TRANSCEND trials, together and grouped by atrial fibrillation status

\begin{tabular}{|c|c|c|c|c|c|}
\hline Characteristic & $\begin{array}{c}\text { All participants, } \\
\text { no. }(\%)^{*} \\
n=31506\end{array}$ & $\begin{array}{c}\text { No atrial fibrillation, } \\
\text { no. }(\%)^{*} \\
n=29916\end{array}$ & $\begin{array}{l}\text { Atrial fibrillation at } \\
\text { baseline, no. }(\%)^{*} \\
n=1016\end{array}$ & $\begin{array}{l}\text { Atrial fibrillation } \\
\text { at follow-up, } \\
\text { no. }(\%)^{*} \\
n=2052\end{array}$ & $p$ valuet \\
\hline Age, yr, mean (SD) & $66.5 \quad(7.2)$ & $66.3 \quad(7.2)$ & $70.3 \quad(6.9)$ & $69.0 \quad(7.1)$ & $<0.001$ \\
\hline Baseline MMSE & $27.7 \quad(2.9)$ & $27.7 \quad(2.9)$ & $27.0 \quad(3.5)$ & $27.6 \quad(3.0)$ & $<0.001$ \\
\hline Female sex & $9360 \quad(29.7)$ & 8885 (29.7) & $277(27.3)$ & $526(25.6)$ & $<0.001$ \\
\hline $\begin{array}{l}\text { Creatinine level, } \mu \mathrm{mol} / \mathrm{L} \text {, } \\
\text { mean (SD) }\end{array}$ & 93.9 (24.6) & $93.7(24.4)$ & $99.4(27.5)$ & $98.2(25.6)$ & $<0.001$ \\
\hline $\begin{array}{l}\text { Systolic BP, mmHg, mean } \\
\text { (SD) }\end{array}$ & $141.6(17.3)$ & $141.7(17.3)$ & $139.2(17.9)$ & $143.8(17.5)$ & 0.02 \\
\hline $\begin{array}{l}\text { Change in systolic BP, } \\
\mathrm{mmHg} \text {, mean (SD) }\end{array}$ & $-5.5 \quad(21.8)$ & $-5.5(21.8)$ & $-4.9(23.2)$ & $-8.6(23.1)$ & $<0.001$ \\
\hline BMI, kg/m², mean (SD) & $28.1 \quad(4.5)$ & $28.1 \quad(4.5)$ & $28.5 \quad(4.9)$ & $28.6 \quad(4.7)$ & $<0.001$ \\
\hline Previous MI & 15285 (48.5) & 14569 (48.7) & $418(41.1)$ & $1064(51.8)$ & 0.9 \\
\hline Previous stroke/TIA & $6632(21.0)$ & $6134(20.5)$ & $374(36.8)$ & $475(23.1)$ & $<0.001$ \\
\hline Hypertension & $22116 \quad(70.2)$ & 20985 (70.1) & $760(74.8)$ & $1562(76.1)$ & $<0.001$ \\
\hline Diabetes mellitus & 11719 (37.2) & 11171 (37.3) & $367(36.1)$ & $683(33.3)$ & $<0.001$ \\
\hline Smoking & & & & & $<0.001$ \\
\hline Never & 11846 (37.6) & 11197 (37.4) & 405 (39.9) & $714(34.8)$ & \\
\hline Current & 3802 (12.1) & $3636(12.2)$ & $78 \quad(7.7)$ & $201 \quad(9.8)$ & \\
\hline Former & $15819 \quad(50.2)$ & $15050 \quad(50.3)$ & $533(52.5)$ & $1136(55.3)$ & \\
\hline Alcohol consumption & & & & & $<0.001$ \\
\hline Never/former & 19311 (61.3) & 18338 (61.3) & $602(59.3)$ & $1144(55.7)$ & \\
\hline Moderate & 11596 (36.8) & $11003(36.8)$ & $401(39.5)$ & $861(42.0)$ & \\
\hline Binge drinking & $591 \quad(1.9)$ & $573 \quad(1.9)$ & $13 \quad(1.3)$ & $47 \quad(2.3)$ & \\
\hline Level of education & & & & & 0.04 \\
\hline None & 1156 & 1080 & $38 \quad(3.7)$ & $76 \quad(3.7)$ & \\
\hline $1-8 \mathrm{yr}$ & $9482 \quad(30.1)$ & $8962(30.0)$ & $341(33.6)$ & $580(28.3)$ & \\
\hline $9-12 y r$ & 9305 (29.5) & $8816(29.5)$ & $301(29.6)$ & $605(29.5)$ & \\
\hline Trade/technical & $5613(17.8)$ & $5338(17.8)$ & $176(17.3)$ & $420(20.5)$ & \\
\hline College/university & $5936(18.8)$ & $5718(19.1)$ & $160(15.7)$ & $371(18.1)$ & \\
\hline Level of physical activity & & & & & 0.1 \\
\hline Sedentary & 7284 (23.1) & 6839 (22.9) & $270(26.6)$ & $453(22.1)$ & \\
\hline Exercise $<1$ time/wk & 3633 (11.5) & $3359(11.2)$ & $129(12.7)$ & $250(12.2)$ & \\
\hline Exercise 2-4 times/wk & $7191 \quad(22.8)$ & $6843(22.9)$ & $213(21.0)$ & $490(23.9)$ & \\
\hline Exercise 5-6 times/wk & $2398 \quad(7.6)$ & 2302 & $80 \quad(7.9)$ & $155 \quad(7.6)$ & \\
\hline Daily exercise & 10982 & 10568 (35.3) & $324(31.9)$ & $704(34.3)$ & \\
\hline Antithrombotic therapy & & & & & $<0.001$ \\
\hline Antiplatelet therapy & $24644 \quad(78.2)$ & 23892 (79.9) & $308(30.3)$ & $1560(76.0)$ & \\
\hline $\begin{array}{l}\text { Anticoagulant therapy or } \\
\text { antiplatelet and } \\
\text { anticoagulant therapy }\end{array}$ & $2357 \quad$ (7.5) & 1668 & $634(62.4)$ & $262(12.8)$ & \\
\hline Statin therapy & $19036 \quad(60.4)$ & $18204(60.9)$ & $509(50.1)$ & $1279(62.3)$ & $<0.01$ \\
\hline Ramipril & 8564 (27.2) & $8133(27.2)$ & $273(26.9)$ & $585(28.5)$ & 0.6 \\
\hline Telmisartan & $11482 \quad(36.4)$ & 10905 (36.5) & $375(36.9)$ & $742(36.2)$ & \\
\hline $\begin{array}{l}\text { Combination therapy } \\
\text { (ramipril and telmisartan) }\end{array}$ & $8491 \quad(27.0)$ & $8056(26.9)$ & $275(27.1)$ & $543(26.5)$ & \\
\hline Placebo & $2969 \quad(9.4)$ & $2822 \quad(9.4)$ & $93 \quad(9.2)$ & $182(8.9)$ & \\
\hline
\end{tabular}


Stroke during follow-up was determined by an adjudication committee.

\section{Statistical analysis}

We compared the baseline differences in characteristics among participants in different categories of MMSE score using $\chi^{2}$ and $t$ tests. We used Cox model regression to generate models for each of the following four outcomes, and their composite: decline in MMSE score by three or more points from baseline to follow-up (only those participants with a baseline score and at least one follow-up MMSE were included); new dementia (as defined previously); new loss of independence for activities of daily living; and admission to long-term care. For the analyses of admission to long-term care and new loss of independence for activities of daily living, we included those participants who had not reported these outcomes at baseline (i.e., participants not living in long-term care facilities and those able to perform activities of daily living independently). We included atrial fibrillation, at baseline and/or at follow-up, as a predictor variable in all models.

To explore the influence of antithrombotic treatment, we categorized atrial fibrillation by antithrombotic status (i.e., no antithrombotic treatment $\mathrm{v}$. antithrombotic treatment with either antiplatelet therapy or anticoagulants). We adjusted all models for the following confounders: age; level of education; sex; baseline MMSE score; systolic blood pressure at baseline; history of stroke or transient ischemic attack, hypertension, diabetes and myocardial infarction; levels of microalbuminuria, macroalbuminuria, and creatinine; treatment with statins, $\beta$-blockers, angiotensin-converting enzyme inhibitors, antiplatelet therapy or oral anticoagulants; changes in systolic blood pressure during follow-up; smoking; body mass index; level of physical activity; presence of sleep apnea; and alcohol consumption. On subgroup analysis, we explored the association separately among participants with and without clinical stroke (previous, reported at baseline or during follow-up), by trial, treatment group and ethnicity (European v. non-European). To consider regional variations, we created a marginal model to account for clustering that showed no change in the results.

\section{Results}

In total, 31506 participants from the ONTARGET and TRANSCEND trials were enrolled in our study. Loss to follow-up was $0.02 \%$, and median follow-up was 56 months. The mean age of participants at baseline was 66.5 years, and the mean MMSE score was 27.7 (standard deviation [SD] 2.9) (Table 1). At baseline, 1016 participants had atrial fibrillation, and the condition was diagnosed in an additional 2052 patients during the follow-up period (Table 1). Of all 3068 participants with atrial fibrillation (baseline and follow-up), 896 $(29.2 \%)$ were taking oral anticoagulants and 1868 (60.9\%) were receiving antiplatelet therapy; 304 (9.9\%) patients with atrial fibrillation were not receiving antithrombotic therapy. Participants with atrial fibrillation at baseline had lower MMSE scores, were older, received fewer years of formal

Table 2: Association between atrial fibrillation (baseline and follow-up) and cognitive and functional outcomes among participants of the ONTARGET and TRANSCEND trials

\begin{tabular}{|c|c|c|c|c|c|}
\hline $\begin{array}{l}\text { Composite } \\
\text { outcome* }\end{array}$ & $\begin{array}{c}n=29916 \\
7972(26.7)\end{array}$ & $\begin{array}{l}n=27864 \\
7269(26.1)\end{array}$ & $\begin{array}{l}n=1016 \\
347(34.1)\end{array}$ & $\begin{array}{c}n=2052 \\
703(34.3)\end{array}$ & $\begin{array}{c}n=3068 \\
1050(34.2)\end{array}$ \\
\hline $\begin{array}{l}\text { Dementia during } \\
\text { follow-up }\end{array}$ & $\begin{array}{l}n=27386 \\
2157(7.9)\end{array}$ & $\begin{array}{l}n=25521 \\
1972 \quad(7.7)\end{array}$ & $\begin{array}{c}n=890 \\
114(12.8)\end{array}$ & $\begin{array}{l}n=1865 \\
185 \quad(9.9)\end{array}$ & $\begin{array}{l}n=2755 \\
299(10.9)\end{array}$ \\
\hline $\begin{array}{l}\text { Loss of } \\
\text { independence in } \\
A D L\end{array}$ & $\begin{array}{l}n=27160 \\
2006(7.4)\end{array}$ & $\begin{array}{l}n=25272 \\
1775 \quad(7.0)\end{array}$ & $\begin{array}{c}n=857 \\
122(14.2)\end{array}$ & $\begin{array}{l}n=1888 \\
231(12.2)\end{array}$ & $\begin{array}{l}n=2745 \\
353(12.9)\end{array}$ \\
\hline
\end{tabular}


education and were more likely to have a history of stroke, myocardial infarction, hypertension, diabetes mellitus, smoking, renal impairment, a sedentary lifestyle and not adhere to their medications (Table 1) than the participants who did not have atrial fibrillation at baseline. Among the 3068 patients with atrial fibrillation, 261 (8.5\%) had an incident stroke during the study period, compared with 1110 (4.0\%) of the 27864 patients who never had atrial fibrillation.

\section{Association between atrial fibrillation and cognitive and functional decline}

The composite outcome of a decrease in MMSE score by three or more points, dementia, admission to a long-term care facility and loss of independence in performing activities of daily living occurred in 7269 (26.1\%) patients without atrial fibrillation and in 1050 (34.2\%) patients with atrial fibrillation (baseline and follow-up). Table 2 shows the rates of individual components of the composite outcome by atrial fibrillation status. On multivariable analysis, atrial fibrillation (baseline and follow-up) was associated with an increased risk of cognitive loss (hazard ratio [HR] 1.14, 95\% confidence interval [CI] 1.03-1.26), new dementia (HR 1.30, 95\% CI 1.14-1.49), loss of independence in performing activities of daily living (HR 1.35, 95\% CI 1.191.54) and admission to a long-term care facility
(HR 1.53, 95\% CI 1.31-1.79). The results were consistent for patients with atrial fibrillation at baseline (HR 1.13, 95\% CI 1.00-1.28) and those in whom atrial fibrillation developed during follow-up (HR 1.22, 95\% CI 1.12-1.32) for the composite of all outcomes (Figure 1).

\section{Antithrombotic therapy}

We did not find the use of antithrombotic agents to modify the association between atrial fibrillation (baseline and follow-up) and the composite of all outcomes. Hazard ratios for patients with atrial fibrillation receiving antithrombotic therapy (HR 1.12, 95\% CI 1.04-1.21) and for those with atrial fibrillation who were not receiving antithrombotic therapy (HR 1.04, 95\% CI 0.65$1.66 ; p=0.7$ for interaction) were similar.

\section{Subgroup analysis}

The results of our subgroup analysis for patients with and without stroke (baseline and follow-up) were consistent in both groups (Table $3 ; p=0.5$ for interaction for composite outcome). The results of other subgroup analyses showed no significant interactions for composite outcomes (Table 4).

\section{Interpretation}

We found that atrial fibrillation was an important risk factor for cognitive and functional decline

\begin{tabular}{|c|c|c|c|c|c|c|}
\hline Outcome & HR $(95 \% \mathrm{CI})$ & & HR $(95 \% \mathrm{CI})$ & \multicolumn{3}{|c|}{ HR $(95 \% \mathrm{CI})$} \\
\hline $\begin{array}{l}\text { Decrease in MMSE } \\
\text { score } \geq 3\end{array}$ & $1.18(0.99-1.41)$ & - & $1.11(0.99-1.24)$ & - & $1.14(1.03-1.26)$ & - \\
\hline $\begin{array}{l}\text { Dementia during } \\
\text { follow-up }\end{array}$ & $1.41(1.13-1.76)$ & $\rightarrow-$ & $1.23(1.05-1.44)$ & - & $1.30(1.14-1.49)$ & $\rightarrow$ \\
\hline $\begin{array}{l}\text { Loss of independence in } \\
\text { ADL during follow-up }\end{array}$ & $1.27(1.03-1.58)$ & $\rightarrow-$ & $1.35(1.16-1.56)$ & $\rightarrow$ & 1.35 ( 1.19-1.54) & $\rightarrow$ \\
\hline $\begin{array}{l}\text { Admission to } \\
\text { long-term care } \\
\text { during follow-up }\end{array}$ & $1.44(1.10-1.89)$ & $\longrightarrow$ & $1.53(1.28-1.82)$ & $\rightarrow-$ & $1.53(1.31-1.79)$ & - \\
\hline \multirow[t]{3}{*}{ Composite outcome } & $1.13(1.00-1.28)$ & - & $1.22(1.12-1.32)$ & - & $1.20(1.12-1.29)$ & 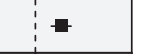 \\
\hline & \multicolumn{2}{|c|}{0.5} & 0.5 & 1.0 & 0.5 & 1.0 \\
\hline & \multicolumn{2}{|c|}{$\begin{array}{c}\text { Atrial fibrillation } \\
\text { at baseline } v . \\
\text { no atrial fibrillation }\end{array}$} & \multicolumn{2}{|c|}{$\begin{array}{c}\text { New atrial fibrillation } \\
\text { no new } \\
\text { atrial fibrillation }\end{array}$} & \multicolumn{2}{|c|}{$\begin{array}{c}\text { Atrial fibrillation } \\
\text { (baseline and follow-up) v. } \\
\text { no atrial fibrillation }\end{array}$} \\
\hline
\end{tabular}

Figure 1: Multivariable association between atrial fibrillation (at baseline and during follow-up) and cognitive and functional outcomes. Models were adjusted for the following confounding variables: age; level of education; sex; baseline MMSE score; systolic blood pressure at baseline; history of stroke or transient ischemic attack, hypertension, diabetes and myocardial infarction; levels of microalbuminuria, macroalbuminuria and creatinine; treatment with statins, $\beta$-blockers, angiotensin-converting enzyme inhibitors, antiplatelet therapy or oral anticoagulants; changes in systolic blood pressure during follow-up; smoking; body mass index; level of physical activity; presence of sleep apnea; and alcohol consumption. Hazard ratios greater than 1.00 suggest increased risk of the specified outcome. The composite outcome was a decrease in MMSE score of 3 points or more, new diagnosis of dementia at follow-up, loss of independence with performing $A D L$ and admission to a long-term care facilty. $A D L=$ activities of daily living, $\mathrm{Cl}=\mathrm{confidence}$ interval, HR = hazard ratio, MMSE = Mini-Mental State Examination. 
Table 3: Adjusted* association between atrial fibrillation and cognitive and functional outcomes for participants with stroke (previous or at follow-up) and without stroke

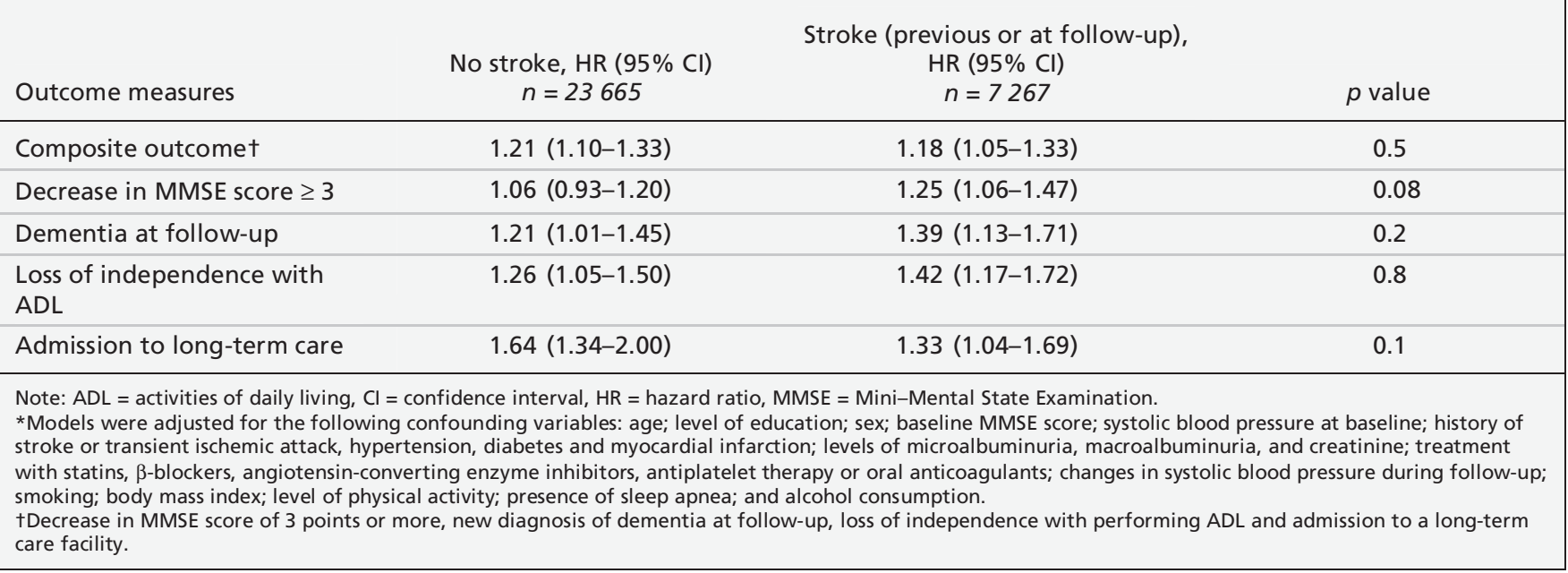

Table 4: Multivariable association between atrial fibrillation (at baseline or follow up) and cognitive and functional outcomes in subgroups of patients defined by occurrence of stroke (previous history or during follow-up) by recruitment, ethnicity or treatment with ACE inhibitors or angiotensin receptor blockers

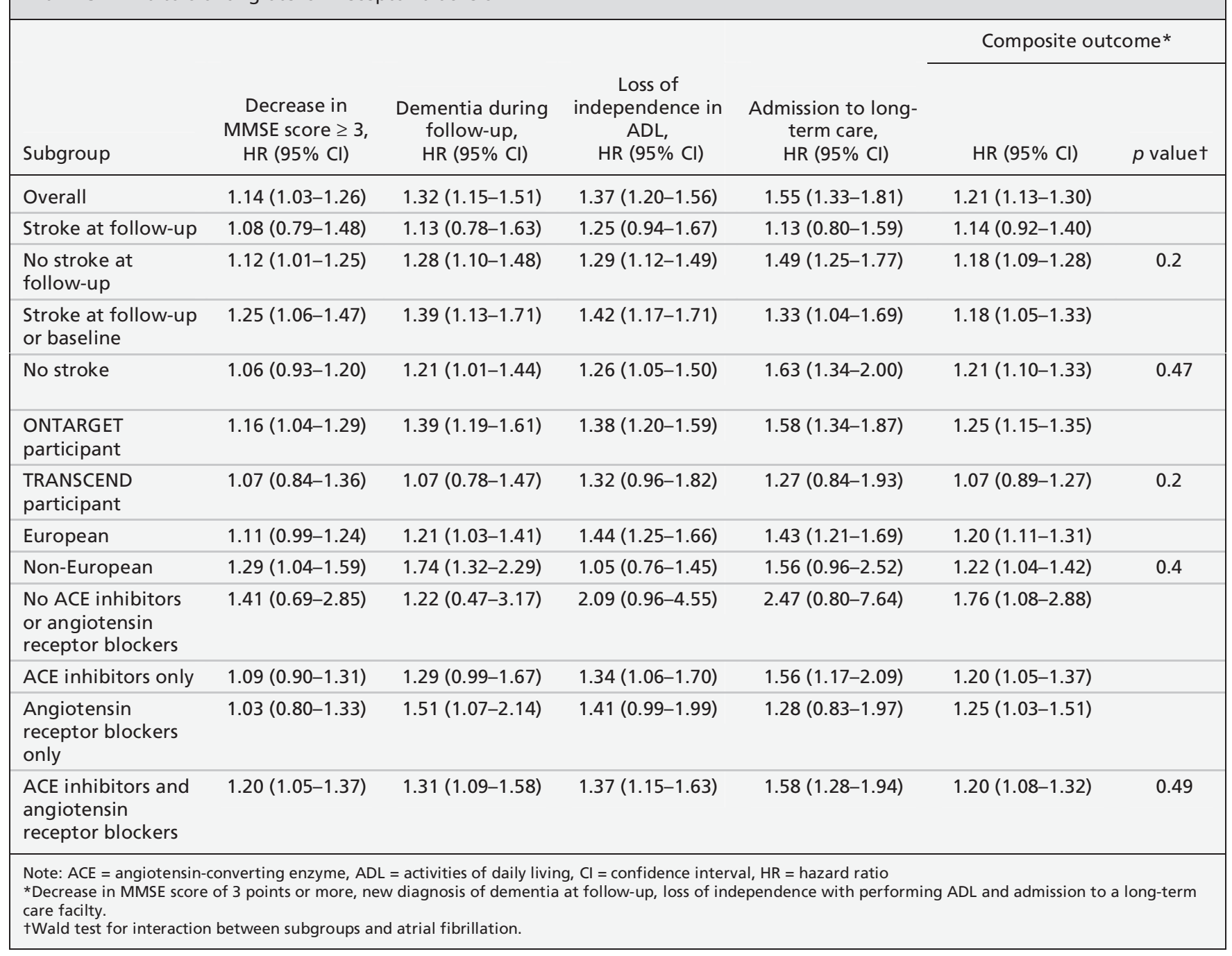


among participants of the ONTARGET and TRANSCEND trials. This association was independent of previous or incident clinical stroke and treatment with antihypertensive drugs.

The largest study to evaluate the association between atrial fibrillation and cognitive impairment was the cross-sectional portion of the Rotterdam study. ${ }^{11}$ That study $(n=6584)$ found a significant association between atrial fibrillation and cognitive impairment. However, a subsequent prospective cohort study did not report a positive relation between atrial fibrillation and cognitive decline after three years' follow-up, although the size of the sample $(n=362)$ was inadequate to detect a modest association. ${ }^{13}$

Our study provides prospective evidence that atrial fibrillation increases the risk of cognitive decline and dementia, independent of clinically overt stroke and baseline cognitive function. This association was seen among participants with known atrial fibrillation at baseline, and among those in whom the condition developed during follow-up.

In addition to an association with cognitive decline, we also saw a significant association between atrial fibrillation and functional decline (loss of independence with activities of daily living) and the need for long-term care. This decline may suggest an increased prevalence and incidence of subclinical cerebrovascular disease. ${ }^{2}$ Subclinical cerebrovascular disease includes covert infarction, white matter hyperintensities, cerebral atrophy and microbleeds..$^{22}$ In particular, periventricular white matter disease is common and is associated with cognitive and functional decline. ${ }^{23}$ Executive dysfunction results in psychomotor slowing with resultant impairments in multitasking, task-sequencing and working memory. ${ }^{23}$ As a result, patients will notice increased difficulty completing instrumental activities of daily living. In addition to cognitive dysfunction, manifestations of covert ischemia may increase dependence and include abnormalities in a person's gait or movement (e.g., vascular Parkinsonism). ${ }^{24-26}$ Therefore, covert stroke may promote functional loss through a number of intermediate mechanisms resulting from a spectrum of covert and overt cerebrovascular disease.

Among patients with atrial fibrillation, we saw high rates of cognitive and functional decline and admission to long-term care facilities during the five-year follow-up. Overall, about one-third of patients with atrial fibrillation had at least one of these outcomes, compared with about one-quarter of patients without atrial fibrillation. In comparison, the rates of clinical stroke were much lower (reported in $4.5 \%$ of participants).
Our findings highlight the need to include cognitive and functional measures in clinical trials of patients with atrial fibrillation.

\section{Limitations}

The participants of our study were people who had been included in a large randomized controlled trial, and may not be representative of consecutive patients in real-life practice. Moreover, the patients included in our study have multiple risk factors for cardiovascular disease, some of which are known to be correlated with cognitive or functional decline.

We recognize that our results may be applicable only to people with characteristics similar to those of the patients included in the ONTARGET and TRANSCEND studies and would need confirmation with a large prospective cohort study. In addition, patients with established cognitive impairment were not included in our trial, which limited our ability to detect associations. However, the rates of dementia reported in our study are comparable with those reported in a community-based cohort ${ }^{5}$ that had a prevalence of dementia of $10.5 \%$ at five years' follow-up in patients with atrial fibrillation.

Although we expect that cognitive and functional decline is largely due to covert stroke, patients did not undergo neuroimaging to determine the prevalence, pattern and severity of covert stroke that underlie these clinical changes.

We did not report the influence of antithrombotic therapy on cognitive and functional decline other than for the composite outcome, because of the low proportion of patients who were not receiving antithrombotic therapy $(n=304)$, and decisions to avoid antithrombotic therapy may relate to factors that increase the risk of cognitive and functional decline (e.g., frailty, comorbidities). Accordingly, estimates of association may be misleading and, therefore, not fully evaluated and reported. Ongoing randomized controlled trials of novel anticoagulants, compared with antiplatelet therapy, may provide more definitive answers to this question. ${ }^{27}$

Information on loss of independence in performing activities of daily living was not systematically collected through the use of a validated tool, and details of the types of activities were not reported.

Our cognitive measure, the MMSE, may be insensitive for detecting subtle impairments in executive function, which is preferentially affected in vascular cognitive impairment. ${ }^{28}$

Factors such as social supports, social isolation and limitations in mobility at baseline may be important confounders, but we did not measure them. As such, our analyses may underestimate the 
size of the association between atrial fibrillation and preclinical vascular cognitive dysfunction.

Finally, our definition of dementia was not based on assessments of participants by specialists. Instead, it relied on self-report and MMSE cut-points that, although used in previous studies, have inherent limitations.

\section{Conclusion}

Cognitive and functional decline are common and important consequences of atrial fibrillation, independent of clinical stroke.

\section{References}

1. Albers GW, Dalen JE, Laupacis A, et al. Antithrombotic therapy in atrial fibrillation. Chest 2001;119:194S-206S.

2. Vermeer SE, Longstreth WT Jr, Koudstaal PJ. Silent brain infarcts: a systematic review. Lancet Neurol 2007;6:611-9.

3. Mead GE, Keir S. Association between cognitive impairment and atrial fibrillation: a systematic review. J Stroke Cerebrovasc Dis 2001;10:35-43

4. Knecht $\mathrm{S}$, Oelschläger $\mathrm{C}$, Duning $\mathrm{T}$ et al. Atrial fibrillation in stroke-free patients is associated with memory impairment and hippocampal atrophy. Eur Heart J 2008;29:2125-32.

5. Miyasaka Y, Barnes ME, Petersen RC, et al. Risk of dementia in stroke-free patients diagnosed with atrial fibrillation: data from a community-based cohort. Eur Heart J 2007;28:1962-7.

6. Rastas S, Verkkoniemi A, Polvikoski T, et al. Atrial fibrillation, stroke, and cognition: a longitudinal population-based study of people aged 85 and older. Stroke 2007;38:1454-60.

7. Forti P, Maioli F, Pisacane N, et al. Atrial fibrillation and risk of dementia in non-demented elderly subjects with and without mild cognitive impairment (MCI). Arch Gerontol Geriatr 2007; 44(Suppl 1):155-65

8. Forti P, Maioli F, Pisacane N, et al. Atrial fibrillation and risk of dementia in non-demented elderly subjects with and without mild cognitive impairment. Neurol Res 2006;28:625-9.

9. Sabatini T, Frisoni GB, Barbisoni P, et al. Atrial fibrillation and cognitive disorders in older people. J Am Geriatr Soc 2000;48: 387-90.

10. Rozzini R, Sabatini T, Trabucchi M. Chronic atrial fibrillation and low cognitive function. Stroke 1999;30:190-1.

11. Ott A, Breteler MM, de Bruyne MC. van HF, Grobbee DE, Hofman A. Atrial fibrillation and dementia in a population-based study. The Rotterdam Study. Stroke 1997;28:316-21.

12. O'Connell JE, Gray CS. Atrial fibrillation and cognitive impairment. Lancet 1992;340:1169.

13. Park H, Hildreth A, Thomson R, et al. Non-valvular atrial fibrillation and cognitive decline: a longitudinal cohort study. Age Ageing 2007;36:157-63

14. Bilato C, Corti MC, Baggio G, et al. Prevalence, functional impact, and mortality of atrial fibrillation in an older Italian population (from the Pro.V.A. study). Am J Cardiol 2009;104:1092-7.

15. Kwok CS, Loke YK, Hale R, et al. Atrial fibrillation and incidence of dementia: a systematic review and meta-analysis. Neurology 2011;76:914-22.
16. Yusuf S, Teo K, Anderson C, et al. Effects of the angiotensinreceptor blocker telmisartan on cardiovascular events in high-risk patients intolerant to angiotensin-converting enzyme inhibitors: a randomised controlled trial. Lancet 2008;372:1174-83.

17. Yusuf S, Teo KK, Pogue J, et al. Telmisartan, ramipril, or both in patients at high risk for vascular events. N Engl J Med 2008;358: 1547-59.

18. Hensel A, Luck T, Luppa M, et al. Does a reliable decline in Mini-Mental State Examination total score predict dementia? Diagnostic accuracy of two reliable change indices. Dement Geriatr Cogn Disord 2009;27:50-8.

19. Tzourio C, Anderson C, Chapman N, et al. Effects of blood pressure lowering with perindopril and indapamide therapy on dementia and cognitive decline in patients with cerebrovascular disease. Arch Intern Med 2003;163:1069-75.

20. Anstey KJ, Burns RA, Birrell CL, et al. Estimates of probable dementia prevalence from population-based surveys compared with dementia prevalence estimates based on meta-analyses. BMC Neurol 2010;10:62.

21. Cockcroft DW, Gault MH. Prediction of creatinine clearance from serum creatinine. Nephron 1976;16:31-41.

22. Black SE. Vascular cognitive impairment: epidemiology, subtypes, diagnosis and management. $J R$ Coll Physicians Edinb 2011:41:49-56

23. Debette S, Markus HS. The clinical importance of white matter hyperintensities on brain magnetic resonance imaging: systematic review and meta-analysis. BMJ 2010;341:c3666.

24. Hajjar I, Quach L, Yang F, et al. Hypertension, white matter hyperintensities, and concurrent impairments in mobility, cognition, and mood: the Cardiovascular Health Study. Circulation 2011;123:858-65.

25. Murray ME, Senjem ML, Petersen RC, et al. Functional impact of white matter hyperintensities in cognitively normal elderly subjects. Arch Neurol 2010;67:1379-85.

26. Rektor I, Rektorova I, Kubova D. Vascular parkinsonism - an update. J Neurol Sci 2006;248:185-91.

27. Eikelboom JW, O'Donnell M, Yusuf S, et al. Rationale and design of AVERROES: apixaban versus acetylsalicylic acid to prevent stroke in atrial fibrillation patients who have failed or are unsuitable for vitamin K antagonist treatment. Am Heart J 2010;159:348-53.

28. Kasten M, Bruggemann N, Schmidt A, et al. Validity of the MoCA and MMSE in the detection of MCI and dementia in Parkinson disease. Neurology 2010;75:478-9.

Affiliations: From the Population Health Research Institute, McMaster University, Hamilton, Ont., and Mario Negri Institute for Pharmacological Research Milan (Marzona), Milan, Italy; Health Research Board Clinical Research Facility, National University of Ireland Galway, (O’Donnell) Galway, Ireland; Population Health Research Institute (O'Donnell, Teo, Gao, Bosch, Yusuf), McMaster University, Hamilton, Ont.; and The George Institute for Global Health, Royal Prince Albert Hospital and University of Sidney (Anderson), Sidney, Australia

Contributors: Irene Marzona, Salim Yusuf and Martin O'Donnell conceived the study and wrote the first draft of the paper. Peggy Gao analyzed the data. All of the authors wrote the manuscript, revised it for important intellectual content and approved the final version submitted for publication. 